\title{
Competitive Strategy and Total Quality Management Culture in organizations
}

\section{Dr. B. Johnson Ojo}

\begin{abstract}
:
This paper discusses the elements of competitive strategy, total quality management culture and productivity improvement and their relationship in producing better outputs of goods and services and individual and organizational performance. Production remains fundamental to the sustenance of human existence. A productive activity is one that contributes (directly/ indirectly) to the satisfaction of people's wants. The wants are either material (requiring the use of resources provided by nature) or immaterial (requiring the services of other human beings). Production relations are organized around the three main agents of economic activity, including the household, the firm and the govt. given the natural tendency for population growth, outputs of various production processes have to grow for the levels of Socio-economic welfare to rise or at least be sustained at existing levels. In addition, development requires, among other things, output growth as well as access to increasingly wider ranges of goods and services in any economy. The realization of these presupposes a variety of stimuli. Prominent among the necessities are quality and productivity plus a clear and strong strategy to remain afloat in the industrial competitive market. This paper therefore, examines the concept of total qualitative management in a competitive environment within the contexts of globalizations, deregulation and liberalization.
\end{abstract}

\section{Introduction}

Competition in a broader sense can be termed extended rivalry. Quality management consultants agree that implementing quality management strategies requires a change in culture, a change that is often difficult to achieve but since marketing principles need to be changed from mere advertising techniques to customer expectations, then the need for a competitive strategy.

Competitive strategy therefore is the way in which a firm (or an organization) can compete more effectively to strengthen its market position. Developing a competitive strategy is developing a broad formula for how a business is going to compete, what its goals should be, and what polices will be needed to carry out these goals. In other words, competitive strategy is a combination of the ends for which the organization is striving and the means by which it is seeking to get there.

In explaining this term, Michael Porter (1980) condensed the whole essence and came up with what he termed the wheel of competitive strategy(see Figure1). This wheel was used as a device for articulating or explaining the key concepts of an organizational competitive strategy in a simple way.

Porter (1980) explained that in the hub (i.e. center) of the wheel are the goals which are the broad aims or definition of how a firm or an organization should compete and the specific economic and non-economic objectives it must achieve. The spokes of the wheel are the key operating policies with which the goals should be achieved. In each of the wheel, a succinct statement of the key operating policies in that functional area should be derived from the organizations activities, depending on the nature of the organization, management can be more or less specific in articulating these key-operating policies; once they are specified, the concept of strategy can be used. to guide the overall behavior of the firm. 


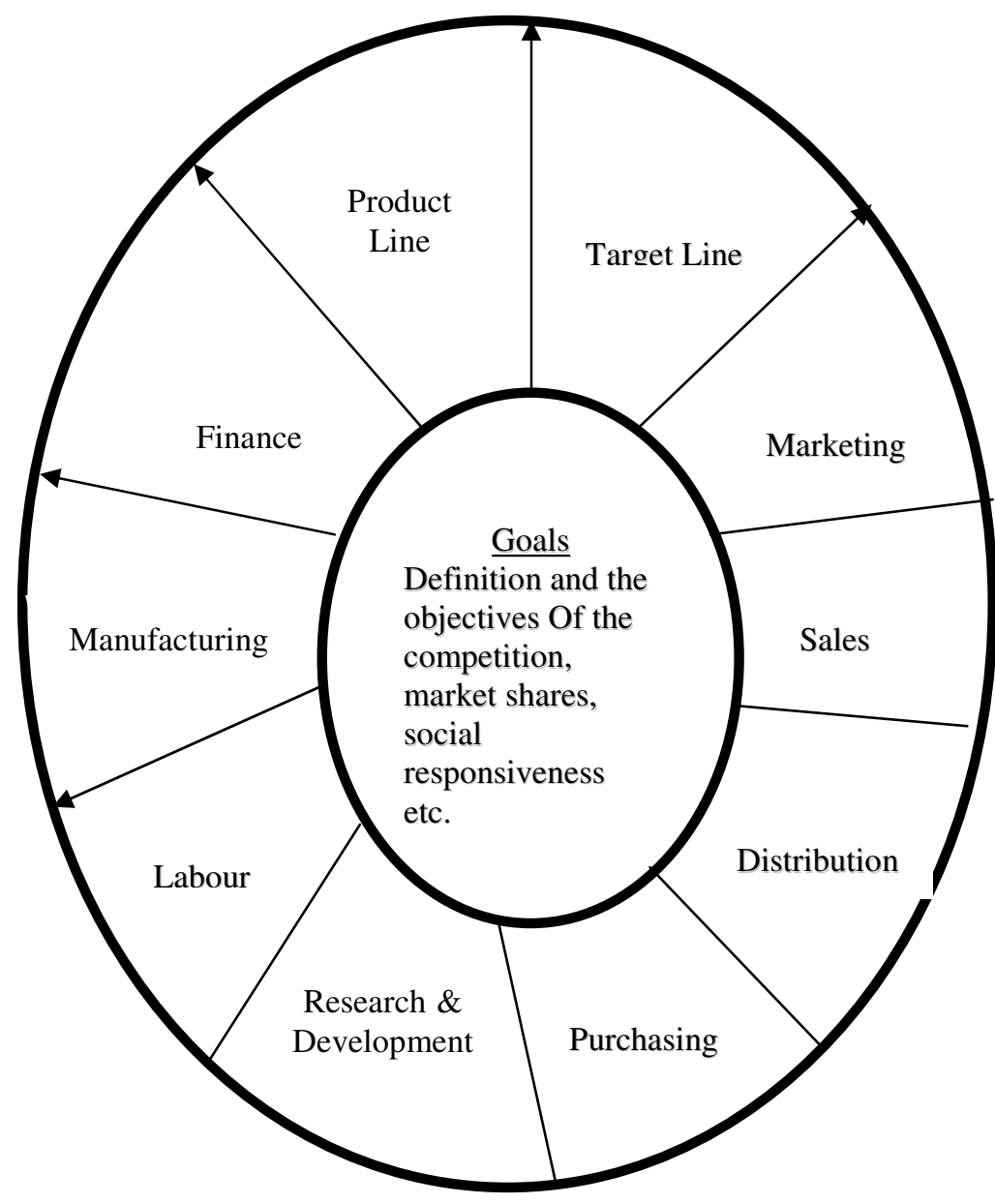

Figure 1 The wheel of competitive strategy-adapted from Porter (1980) 
Like a wheel, the spokes (policies) must radiate from and reflect the hub (goals), and the spokes must be connected with each other or the wheel will not roll.

At the broadest level, formulating competitive strategy involves the consideration of four key elements that determine the limits to what an organization can successfully accomplish. They are

1. Strengths and weaknesses of the organization.

2. Personal values of the key implementers

3. Opportunities and threats (Economic \& Technical)

4. Broader societal expectation (see Figure 2)

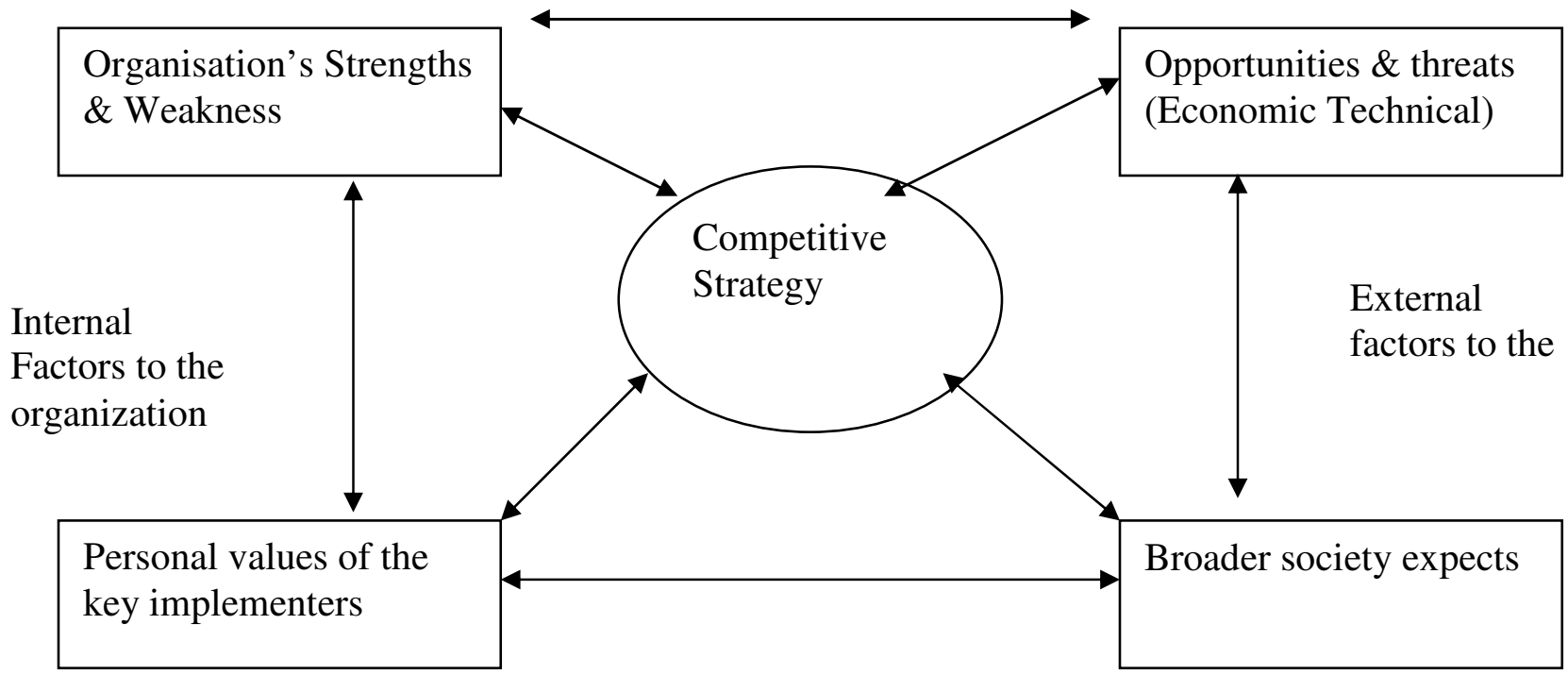

Figure. 2 Competitive strategy formulation contexts

The appropriateness or otherwise of a competitive strategy can be determined by testing the proposed goals and policies for consistency. Andrew (1971) developed a consistency coordinate questions, which are:

A. Internal consistency:-

- $\quad$ Are the goals mutually achievable?

- $\quad$ Do the key operating policies address the goals?

- $\quad$ Do the key operating policies reinforce each other?

B. Environmental fit: -

- $\quad$ Do the goals and policies match exploit industry opportunities

- Do the goals and policies deal with industry threats (including the risk of competitive response) to the degree possible with available resources?

- $\quad$ Does the timing of the goals and policies reflect the ability of the environment to absorb the actions?

- $\quad$ Are the goals and policies responsive to broader societal concerns?

C. Resource fit: -

- Do the goals and policies match the resources available to the company relative to competitors? 
- Does the timing of the goals and policies reflect the organizations ability to change?

D. Communication and implementation:

- Are the goals well understood by the key implementers?

- is there enough congruence between the goals and policies and the values of the key implementers to insure commitment?

- Is there sufficient managerial capability to allow for effective implementation?

This could be explained diagrammatically (see Figure 3) thus:

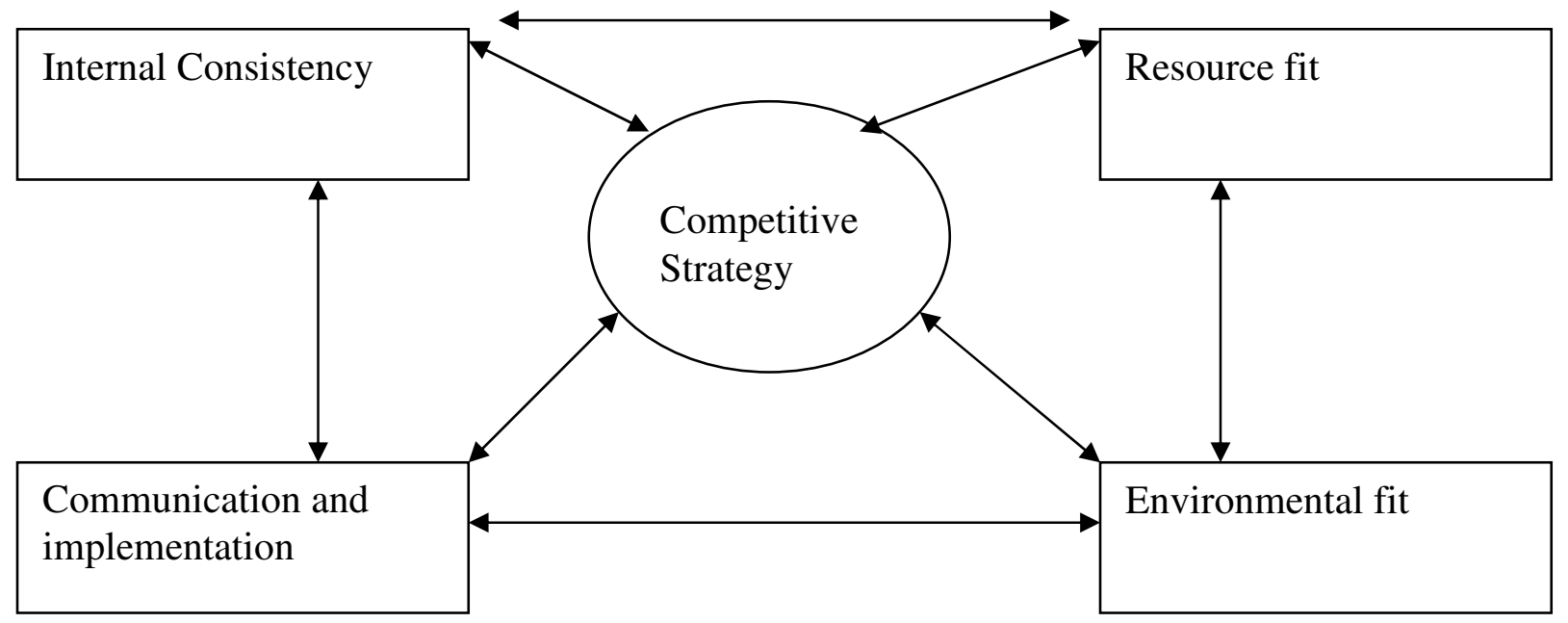

Figure 3 Coordinates of Competitive Strategy

To formulate an effective competitive strategy therefore, the following process must be followed: -

A. What is the Business doing now?

i. Identification

What is the implicit or explicit current strategy?

ii. Implied Assumptions

What assumptions about the company's relative position, strengths and weakness, competitors and industry trends must be made for the current strategy to make sense?

B. What is happening in the Environment?

i. Industry analysis

What are the key factors for competitive success and the important industry opportunities and threats?

ii. Competitor analysis 
What are the capabilities and limitations of existing and potential competitors?

iii. Societal analysis

What important governmental, social, and political factors will present opportunities or threats?

iv. Strengths and weaknesses

Given an analysis of industry and competitors, what are the company's strengths and weakness relative to present and future competitors?

C. What should the Business be doing?

i. $\quad$ Tests of Assumptions and strategy

ii. Strategic Alternatives

What are the feasible strategic alternatives given the analysis above?

iii. Strategic choice

Which alternative best relates the company's situation to external opportunities and threats?

The argument that may arise here could be, what kind of organization can this strategy work effectively for? Is it the industry or the service sector i.e. the social services such as government, health and education? The argument has been that the industry produces goods that are usually countable and prices them according to their market value but in service sector, constructing a measurement scale to count these services is not easy as the services are not priced through the market mechanism. The fact remains however that, these services is essential to the existence of market economy. Governments create and implement rules for the operation of the market, educational institutions supply manpower for the market forces and health services help to maintain the productivity of the markets manpower.

It should equally be borne in mind that organizations are human invention created by man to help him achieve ends, which he could not possibly accomplish individually. It is like an organism with a central nervous system and an environment to operate; it can grow, change and can die. So much as it has the following characteristics:
a. Unequivocal collective identity
b. An exact roaster of members
c. A programmed of activity
d. Procedures for replacing members
e. Social entities
f. Goal directed
g. Identifiable boundaries...

It there fore becomes a network of relationships, interactions and interpersonal behaviors with in consciously established structures in human groups as a product of necessity, an offshoot of human need for co-operation and sustainable existence serving a purpose, it (the service sector) must compete other wise, it dies as has been the case with many government establishments today. Life becomes meaningful; the art of governance, polity, religion, education and culture in general becomes meaningful when new ideals are injected into it to generate a deliberate jealousy from other sectors, which is all the essence of a competition. Holding on to an archaic way or the orthodox way of doing things will only frustrate such organization and will eventually lead to its death. 
Quality management culture on the other hand is the lubricant needed for the wheel of competition to keep revolving in any organization.

\section{Concept of Quality Management}

The war of management of organizations has shifted on to the new battleground. In the 1960 's, marketing orientation was the watchword for achieving competitive advantage in schools; in the 1970's manufacturing orientation became the hot topic. Now competition has arrived at the third battlefield - total quality customer service (TQCS), this has therefore become the make or break factor for formal organization it often requires building a new service-oriented culture. The question that has bordered the minds of serious African organizational Behavior scientists is how to assist members of an organization to stop taking decisions on a turned vision, that is a narrow view of their service, and hence a narrow view of how to discharge it. This is because the root of total Quality customer service (TQCS) is deep, used spread and disable.

Jaja (1999) cited in Ojo (2003) in his submission on how TQCS can work with in the educational set up described TQCS as:

$\mathrm{CeTQCS}=\mathrm{F}(\mathrm{s} 1, \mathrm{p} 1, \mathrm{p} 2, \mathrm{i}, \mathrm{m})$

Where

CeTQCS $=$ Competitive edge in discharging educational related services

$\mathrm{s}_{1},=$ Setting the strategy

$\mathrm{s}_{2}=$ Design of TQCS structure

$\mathrm{p}_{1}=$ Good front-line workers policy

$\mathrm{p}_{2}=$ Putting words into action thru good leadership

$\mathrm{i}=$ Good infrastructure

$\mathrm{m}=$ Consistent performance measurement

Total Quality customer service is a work organizational model and a systematic approach to the practice of the management of organization, which demands the adoption of a new unique orientation by all members of the organization. This is because TQCS requires changes in the following:

- Work methods and general organizational process

- General organizational structure

- Individual and group work beliefs

- Work attitudes and behavior patterns.

The term " Quality" has a variety of connotation" and related meanings. In the context of quality management a number of definitions of the term have been put forward. Crosby, standard organization of Nigeria (SON) Juran, Deming, Organization for international standards (ISO), and Feigenbaum all put forward the following definitions

- Conformance to requirements

- Conformance with users' Requirements

- Fitness for purpose or use

- Quality should be aimed at the needs of the customer, present and future 
- The totality of features and characteristics of a product or service that bear on its ability to satisfy stated or implied needs

- The composite of product and service characteristic of marketing, engineering, manufacture and maintenance through which the service in use will meet the expectation of the customer

Oakland (1993) simply said" Quality means meeting the customer requirements"

To my mind, the nature of quality culture system can only be clearly understood, by examining the contextual meanings of the word total and Quality and use these to describe the system in totality.

Total: Connotes full involvement and responsibility of every member of an organization for the nature of the final produce or service that goes to the customers consequently every member of the system should put in his/her maximum levels of effort and skill toward the attainment of the final service (Aina,1992; Jaja,1998; and Ojo 2003 ).

Quality: Could be defined as excellence; it means value and reliability. Oakland (1993) posits that reliability ranks with quality in importance since it is a key factor in many purchasing decisions where alternatives are being considered. He argues further that; many of the general management issues related to achieving product or service quality are also applicable to reliability.

Meeting the customer requirements' definition of quality is not restrictive to the functional characteristics of products and services. Such other factors as 'satisfaction in ownership and 'status symbol' may also count in the purchase of some goods and services. This is where competition and maximum capacity building comes in. Ability of any organization to predict and forecast the future of the market will be put to a total and maximum test here. Many an organization has eclipsed because of not taking this concept seriously or where they tried to anticipate a change in the market forces their prediction was not properly done.

'Quality' in this context does not have the popular meaning of 'best' in any absolute sense, but it means 'best' for certain specifications. Quality in this sense, in the case of a school organization will mean conformity with specifications; it is meeting and/or exceeding customer's expectation. The focus is on nothing less than optimum quality as is perceived by the customers. Total Quality management therefore presupposes that 'customers define quality: This places a great responsibility on the service-providers, to look beyond education, experience and international standards and towards the customer in order to find out his or her expectations. The problem is not solved even if the customers' expectations are accurately known; changes in situation or simply the passage of time may lead to different expectations. Although the customers' expectations are subject to a great deal of variation, the service-provider is expected to spend time and money in trying to accurately ascertain them. A customer usually expects the following from the service provider

1. Accountability

2. Affordability (Price)

3. Availability

4. Appearance 
Even at this level, it is again the customer who decides which of the above is most important.

Total quality management is the agreed company-wide and plant wide work structure, documented in-effective, integrated technical and managerial procedure, for guiding the coordinated actions of the people, the machines and the information of the company and plant, in the best and most practical way to assure customer quality satisfaction and economical cost of quality. The emphasis in quality management therefore is on information in the coordination of activities and customer expectations when deciding on the type of product (kirithana, 2004)

Edosomwan (1994) cited in Ojo, (2003) identified certain structural components of the total quality management system (TQCS) from the educational standpoint as:

- Continuous process improvement, through constant process audit, and continuously sustained learning actions, resulting in quality enhancement;

- $\quad$ Existence of Quality chains of external and internal customers and suppliers, and the conception of the school system as a boundary-less organization,

- Members empowerment to make operational decisions toward process efficiency, to result in quality improvement;

- Organizational reconfiguration as a set of horizontal process, wherein actions of individuals and units are organized around processes to facilitate task accomplishment;

- Organizational culture pervaded by individual members' consciousness, in every work activity to " Do the right thing right the first, and every time"

TQCS therefore involves the application of quality management principle to all aspects of the business, including customers and suppliers. It focuses primarily on people and processes in the organization.

There are therefore certain situations that should exist with in and among members of an organization especially a school system, in order to make the operation by the TQCS possible. These are as follows:

1. Visionary and quality-driven leadership and follower ship as demonstrated in the enactment of, and adherence to well-articulated quality (policy for the organization, the dept, and/or the work-group and general unalloyed commitment to quality in all organizational activities)

2. Effective communication habits, skills and general behavior as shown in verbal, written and visual aspects.

3. Receptivity to interdependence, team work and free exchange of ideas, knowledge and information

4. Interpersonal trust and opportunities for inter-personal social relations

5. Members psychological attachment to the organization

6. Use of Quality cycles

The effective installation and functioning of TQCS in our organizations demands specific changes in minds of all members of the organization, from the old to the new work orientation. A point that must be stressed is that any activity, task or job that does not contribute towards the attainment of a quality outcome, must be eliminated.

The sustenance of TQCS culture invariably will raise our organization to greater heights, with the consequent enhancement in the well being of members of our organizations. It should be noted that TQCS is the latest and the greatest in the modern world of work 
organization practice, and the managers must all resolve individually and collectively, not to be left out in its train. The adoption of TQCS in any organization results in improved quality of working life for all members of the organization, and that is one of the major reasons why the system is the direction toward which the modern world of excellent management of organizations industry or service provider has turned. Dake and Bunnery (1999) (cited in Ojo2003) submitted that the spread of the TQM philosophies would also be expected to be accompanied by greater sophistication in the application of the tools and techniques and increased emphasis on people. The process will also extend beyond the organization to include partnerships with suppliers and customers. Activities will be reoriented to focus on the customer. They summed TQM as the mutual cooperation of everyone in an organization and associated business process to produce products and services, which meet the needs and expectations of customers.

\section{Innovation, Design And Improvement}

The quest for continuous meeting of customer needs, and the moving target that is quality, impose a need for new approaches on a continual basis innovation is a crucial aspect of this requirement. Innovation entails both the invention and design of radically new products and services. This will embody novel ideas, discoveries and advanced technologies. It will also cover the continuous development and improvement of existing products, services, and process to enhance their performance and quality. Three principles in the innovations of successful organizations have been identified to include:

- Strategic balance to ensure that both old and new product/service developments are important

Top management approach to design which sets the tone and ensure that commitment is a common objective

- $\quad$ Teamwork by which it is ensured that once projects are underway, specialist imputes are fused and problems are tackled simultaneously.

\section{Conclusion:-}

The paper has tried to visualize that the world and the market mechanism are not static but rapidly going on a revolutionary change due to changes. World economy shows a large growth rates and the competitive market forces kept rising daily. Economists have predicted that this trend may remain for the next 25 years. It is expected of a responsible management to get into the attacking front in the war for quality in order to remain afloat, pushing their professionals beyond their book knowledge to new innovations in order to beat back all forms attack. Elements of quality management and their relationship with productivity improvement were discussed. The interface between quality and productivity was perceived as the avoidance of wastage, maximization of output from given input and zero defects in production. Thus quality encapsulates productivity and quality management will encompass productivity improvement.

\section{References}

Aina Sola (1992): Personal management in Nigeria A worker centered Approach edition, Lagos, F. Communication

Crosby.B.Philip (1985) Quality without Tears: The art of Hassle-free management, New York McGraw -Hill 
Ganan Kirithana (2004): Total Quality management; A system to implement, New Delhi. UBS publishers

Jaja, S.A. (1998): Teacher behavior modifications in quality management system:

The police school system in perspective. Lagos, PEN, FH

Oakland, I.S (1993) total Quality Management: the Route to improving performance, Oxford, Butter work -Heinemann

Ojo, B. Johnson (2003): Commandant managerial capacity and workers productivity in the Nigeria Police force schools. Unpublished doctoral dissertation, University of lbadan. Nigeria;

Uga, E.O (2002): " setting and Management of Quality standards" a paper presented at the Training programme on Total Quality management for staff of the central Bank of Nigeria, CBN training center, satellite town, Lagos, June 12-16

Porter Michael (1980) Competitive Strategy: Techniques for Analyzing Industries and Competitors. London, Macmillan Publishers 